\title{
Nucleation of $\mathrm{CaCO}_{3}$ polymorphs from a colloidal alcoholic solution of $\mathrm{Ca}(\mathrm{OH})_{2}$ nanocrystals exposed to low humidity conditions
}

\author{
L.S. Gomez-Villalba*, P. López-Arce and R. Fort \\ Instituto de Geociencias IGEO (CSIC-UCM), Calle Jose Antonio Nováis 2,
}

Madrid 28040, Spain

*Corresponding author: luzgomez@geo.ucm.es

Abstract A study of the stability of calcium carbonate polymorphs formed as a result of the carbonation process from an alcoholic colloidal solution of nanocrystals of $\mathrm{Ca}(\mathrm{OH})_{2}$ in low relative humidity $(\mathrm{RH})$ conditions $(33 \%$ and $54 \% \mathrm{RH}$ ) is presented in this research. The crystalline behaviour, the time dependence of nucleation and the phases transformations as a result of exposure to low humidity conditions are evaluated. The carbonation process is slow, starting with the nucleation of amorphous calcium carbonate, associated to an amorphization process that affects both the portlandite $\left(\mathrm{Ca}(\mathrm{OH})_{2}\right)$ and the initial unstable $\mathrm{CaCO}_{3}$ polymorphs. The excess of alcohol in the solution decreases the surface tension and the nucleation is accelerated by the fast evaporation of the solvent, which avoids the particles to diffuse to their lowest energy sites, giving smaller particles with lower crystallinity as RH decreases.

Keywords: Colloidal $\mathrm{Ca}(\mathrm{OH})_{2}$ nanoparticles, $\mathrm{CaCO}_{3}$ polymorphs, relative humidity, cell parameters

\section{Introduction}

The calcium carbonate or carbonation reaction, obtained spontaneously from the reaction of calcium hydroxide (portlandite) is a process that concerns to research and application fields as diverse as biomineralization processes [1], [2], medical and pharmacological applications [3], [4], or as a product binder to improve the cohesion of highly porous materials [5]. Furthermore, its stability is very useful in the paper industry [6], in the restoration and conservation of paintings and sculptures [7], [8], or in the concrete and Portland cement industry [9]. In the field of environmental science, researches refer to many aspects related to the precipitation of calcium carbonate, which depends on atmosphere, climate and/or local environmental variations such as, $\mathrm{CO}_{2}$ partial pressure, temperature, $\mathrm{pH}$ or $\mathrm{RH}$ [10], that determine the mineral precipitation and phase transformations together with morphological and structural variations. Within this field, may be mentioned many applications such as its usefulness in diagenetic processes [11] or in the assessment of paleoclimate changes based on paleoenvironmental or radiometric records from $\mathrm{CaCO}_{3}$ speleothems [12]. Most studies about phase transformations of $\mathrm{CaCO}_{3}$ have been carried out in aqueous environments [13]. However, alcohol / water solutions are also used in many applications, being necessary to establish its behaviour at nanoscale dimensions at specific humidity conditions and exposure time.

Calcium carbonate may be found in the form of six polymorphs with different structures depending on the atomic sites of $\mathrm{Ca}^{2+}$ or $\mathrm{CO}_{3}{ }^{=}$ions arrangement, and could be found as anhydrous or hydrated polymorphs according to the presence or absence of water molecules. Three anhydrous polymorphs are known: calcite, the most thermodynamically stable (rhomboedral), chemically identical to aragonite (orthorhombic), and vaterite (hexagonal), the most unstable. Amongst the hydrated calcium carbonates, there are differences related to the content of water molecules that are present within the structure. Two polymorphs are known: monohydrocalcite (trigonal) (MHC) with one water molecule $\left(\mathrm{CaCO}_{3} \cdot \mathrm{H}_{2} \mathrm{O}\right)$, and ikaite (monoclinic) with six water molecules $\left(\mathrm{CaCO}_{3} \cdot 6 \mathrm{H}_{2} \mathrm{O}\right)$. There is also a type of amorphous calcium carbonate (ACC).

The use of $\mathrm{Ca}(\mathrm{OH})_{2}$ nanoparticles has become an alternative to improve the consolidation of cultural heritage carbonate rocks [14], [15], [16], [17]. However, considering that the microstructural characteristics of nanoparticles and their stability may differ depending on the synthesis conditions, even from a same colloidal method, giving rise to differences in the nucleation rate, it is necessary to conduct a complete study of crystalline nanoparticles under external 
agents such as relative humidity and time of exposure, including their phase transformations and morphological changes.

Unlike to the previous works $[10,14]$, where the stability of a colloidal product based on $\mathrm{Ca}(\mathrm{OH})_{2}$ nanoparticles (Nanorestore $®$ at $5 \mathrm{~g} / \mathrm{l}$ ) [18] was studied; in the present study, the goal is to evaluate the structural stability of another commercial product (CaLoSil®), also based on calcium hydroxide nanoparticles. In this case, the precursor solution was obtained by the same colloidal synthesis method, although with different experimental conditions [19]. Never before the variation of unit cell parameters of the polymorphs of calcium carbonate or the portlandite in low humidity conditions has been calculated, nor the nucleation process has been associated with the surface tension fluctuations. These results could contribute to evaluate how the growth mechanism is affected by the extreme low humidity conditions.

Recently, the structural stability of $\mathrm{CaCO}_{3}$ polymorphs and its crystallinity based on a colloidal alcoholic solution of nanocrystals of $\mathrm{Ca}(\mathrm{OH})_{2}(\mathrm{CaLoSil})$ exposed to high humidity conditions have been evaluated [20]. However, it is important to compare the results when the same alcoholic solution is exposed to low humidity conditions. In the present research the carbonation process has taken place from a precursor colloidal solution of $\mathrm{Ca}(\mathrm{OH})_{2}$ nanoparticles by spontaneous growth exposed to low humidity conditions at ambient temperature, in a controlled atmosphere with no extra $\mathrm{CO}_{2}$ flux, no circulating air and without additives.

\section{Experimental Section}

The synthesis method has been already described [20]. A precursor solution based on colloidal nanoparticles of

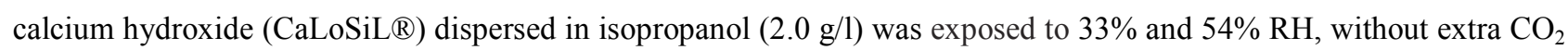
flow and no air in circulation, at $20^{\circ} \mathrm{C}$ for $7,14,21$ and 28 days

X-ray diffraction (XRD) (X'Pert Pro MPD Panalytical X'Celerator diffractometer) was used for the mineral phase identification using the JCPDS database. Rietveld refinements [21] were carried out for unit cell parameters calculation. Environmental scanning electron microscopy (ESEM) (Fei Quanta-EDS Oxford instruments) and Transmission electron microscopy (TEM) -selected area electron diffraction (saed) (Jeol JEM-EDS Link at $200 \mathrm{KV}$ ) were performed for morphological, structural and chemical analyses.

\section{Results and Discussion}

The starting solution (TEM image, Fig. 1a) consists of hexahedral crystals, no aggregated and without preferential orientation (particle size $104 \pm 30 \mathrm{~nm}$ ). When the solution is exposed to low humidity conditions (33 and $54 \% \mathrm{RH})$, initial portlandite crystals undergo a change in the size and phase transformation as a result of constant exposure to this RH as described as follows.

When the solution is exposed to $33 \% \mathrm{RH}$, after 14 days, a poor crystallinity and the beginning of an amorphization process affect the particles. Only few crystals (45.2 to $131.5 \mathrm{~nm})$ of portlandite and vaterite with corroded edges are associated to high content of amorphous calcium carbonate (ACC) (TEM image, Fig. 1b, Fig. 1c). At the same time, when it is exposed to 54\% RH (TEM image, Fig. 1d), corroded crystals (26 to $69 \mathrm{~nm}$ ) of portlandite and prismatic vaterite together with ACC are also identified (TEM image, Fig. 1e). Both saed patterns (Fig. 2b and Fig. 2e) confirm the portlandite and vaterite phases, however the textured ring pattern of the solution exposed to $54 \% \mathrm{RH}$ suggest a higher content of structural defects compared to $33 \%$ RH. TEM images indicate that the crystallinity is slightly higher in the sample exposed to $54 \% \mathrm{RH}$. After 28 days exposed to $33 \% \mathrm{RH}$, portlandite crystals are associated to short prismatic crystals of vaterite (60 to $174 \mathrm{~nm}$ ) (ESEM image, Fig. 2c,) while at 54\% RH, clusters of vateritecalcite polymorphs (72 to $227 \mathrm{~nm}$ ) are associated to ACC (ESEM image, Fig 2f).

The results of XRD (Fig. 2a y Fig. 2d) indicate some differences in the carbonation process. The better definition of the diffraction maxima in the sample exposed to $54 \%$ (Fig. 2d) suggests a better crystallinity. When it is 
exposed to $33 \% \mathrm{RH}$, the background hump (21days) indicates a high amount of ACC which masks the presence of other peaks that are bellow the detection limit. Cell parameters calculated (Table 1) for portlandite and anhydrous calcium carbonate polymorphs indicate that there is a reduction in the size of the unit cell with the increase of the exposure time in both $33 \%$ and $54 \% \mathrm{RH}$. The cell parameters are larger when nucleation has occurred at $54 \% \mathrm{RH}$. Comparing the results achieved with the same solution when it is exposed to high humidity conditions [20] can be verified that the unit cell parameters of the $\mathrm{CaCO}_{3}$ polymorphs in low humidity conditions are shorter and that the smallest cell sizes occur when the RH is lower and when the exposure time has reached 28 days.

Changes in lattice parameters and particle size are related to surface tension fluctuations as observed in high $\mathrm{RH}$ [20]. When the precursor solution is exposed to very low humidity conditions less amount of water is present as vapour phase, and then the initial concentration has high alcohol quantity. Due to the excess of alcohol in the solution, it has lower surface tension than a solution enriched with water vapour. At 33\% RH, the nucleation is accelerated by the fast evaporation of the solvent, which avoids the particles to diffuse to their lowest energy sites during evaporation giving rise to smaller particles with low crystallinity. This is the reason of having a short distance order in calcium carbonates and high disorder degree in portlandite contributing to the development of the ACC phase from portlandite. In the case of high humidity conditions [20], more amount of water is present as vapour phase, and it modifies the concentration of the precursor solution by increasing the water content. The excess of water in the solution has increased the surface tension. The slow evaporation rate allows the particles to diffuse towards their lowest energy sites during evaporation generating particles with high crystallinity [20].

These results confirm that there is a relationship between the calcium carbonate polymorphs transition and the solvent composition in terms of volume ratio of alcohol/water. This polymorphism has been discriminated by Fen et al. [22] observing the development of different habits or correlating the presence of aragonite, vaterite or calcite with the ethanol/water ratio under mild conditions $\left(90^{\circ} \mathrm{C}\right)$ without using any organic additives. These authors obtained vaterite with traces of aragonite in a solution predominantly constituted by ethanol, and pure aragonite when water predominates. When the ethanol/water ratio is $1 / 1$ they obtain aragonite with vaterite traces. In our case, different polymorphs are formed by modification of the RH: 33\%RH (alcohol>water), 54\%RH (alcohol water), 75\%RH ( 1/3 alcohol/water), and 90\%RH (water>>alcohol). Daniele and Taglieri [15] have studied the influence of concentration and residual water content on the carbonation process and on treatment effectiveness to consolidate stone materials. In their experiments, carried out at $40 \%, 70 \%$ and $90 \% \mathrm{RH}$ with $\mathrm{Ca}(\mathrm{OH})_{2}$ nanoparticles suspensions in isopropanol (which destroys the random orientation of the crystals), the residual water and the concentration clearly affect the carbonation process efficiency (yield) controlled after 30min, 1 day and 30 days. Yields increase from 1 to $70 \%$ by varying the water/isopropanol ratios from 0.01 to 1 , respectively. In this work, the higher alcoholic solution is the suspension exposed to $33 \% \mathrm{RH}$.

The carbonation process has been faster in the sample exposed to $54 \% \mathrm{RH}$. In both environments, the carbonation starts with the nucleation of anhydrous polymorphs as confirms the formation of the metastable vaterite phase. Throughout the process, there is a low crystallinity as confirmed by the presence of ACC and the amorphization of minerals. In very low humidity conditions $(33 \% \mathrm{RH})$, portlandite increases with time while vaterite decreases due to its metastable character. Neither aragonite nor calcite nor monohydrocalcite have been formed after 28 days. When the solution is exposed to $54 \% \mathrm{RH}$, the transformation of portlandite into calcium carbonate polymorphs is presented as ACC accompanied of unstable intermediate polymorphs (vaterite and aragonite) with a slow nucleation of calcite phase. The carbonation is being affected by the low amount of water and both dissolution and diffusion of calcium carbonates are considerably slow in alcoholic solutions. Changes in the crystal phases have been observed in synthesis processes of amorphous calcium carbonation in ethanol when they are exposed to aqueous solutions [23]. The nucleation of 
polymorphs of $\mathrm{CaCO}_{3}$ is different depending on the exposure conditions. In high humidity [20] the nucleation of calcite, the most stable $\mathrm{CaCO}_{3}$ polymorph is faster than in low humidity conditions. The catalytic action of water provides a better crystallinity and a faster crystal growth. In contrast to the phase transformations in high humidity conditions [20], the carbonation process in low humidity conditions occurs more slowly, being associated to an amorphization process that affects both the portlandite and the unstable phase (vaterite). Carbonation starts with the nucleation of amorphous carbonates (ACC). The amorphization process in portlandite has been observed in high pressure compression tests [24], however the present work confirms that it can also be achieved in conditions of low humidity at room temperature.

\section{Conclusion}

The crystalline behaviour of nanoparticles of $\mathrm{Ca}(\mathrm{OH})_{2}$ as a result of the exposure to low humidity conditions at $33 \%$ and $54 \%$ RH is slightly different. The carbonation process is slow, starting with the nucleation of carbonates in short range order (ACC) associated to an amorphization process, which affects both the portlandite and the initial unstable $\mathrm{CaCO}_{3}$ polymorphs. The process has been faster in the sample exposed to $54 \% \mathrm{RH}$. Surface tension fluctuations affect their stability and crystallinity. The excess of alcohol in the solution, decreases the surface tension, the nucleation is accelerated by the fast evaporation of the solvent, which avoids the particles to diffuse to their lowest energy sites during evaporation giving smaller particles with low crystallinity.

\section{Acknowledgements}

To the Government of the Community of Madrid (Spain), the GEOMATERIALES (S2009/MAT-1629) and CONSOLIDER-TCP (CSD2007-0058) programmes and to the JAE-Doc CSIC contract.

\section{References}

[1] V. S. Harutyunyan, E. S. Abovyan, P. J. M. Monteiro: Phys. Stat. Sol A 200, 2, 307-325 (2003)

[2] M. Obst, J.J. Dynes, J.R. Lawrence, G.D.W. Swerhone, C. Karunakaran, K.V. Kaznatcheev, D. Bertwistle, K. Benzerara, T. Tyliszczak, A.P. Hitchcock: Geochim. Cosmochim. Acta 73 , 14, 4180-4198 (2009)

[3] J.M. Perea, M.Delgado, A.Mayoral, R.Martín, R.Acero, A.García: Zootec. 53, 407-410 (2004)

[4] W. Suchaneka, M. Yoshimuraa: J. Mater. Res., 13, 94-117 (1998)

[5] C. A. Price: Stone Conservation, An Overview of Current Research, (USA, The J. Paul Getty Trust 1996)

[6] T. Enomae, K. Tsujino: Tappi J. 3, 6 (2004)

[7] M.Ambrosi, L. Dei, R.Giorgi, C. Neto, P. Baglioni: Langmuir, 17, 4251-4255 (2001)

[8] P. Baglioni, R.Giorgi: Soft. Matter 293-303 (2006)

[9] M.Galván- Ruiz, J.Hernández, L. Baños J. Noriega-Montes, M.E. Rodríguez-García: J. Mater. Civ. Eng., 694-698, (2009)

[10] P. López-Arce, L.S. Gomez-Villalba, S. Martinez-Ramirez, M. Alvarez de Buergo, R. Fort: Powder Technol., 205, 263-269 (2011)

[11] S. Grasby: Geochim. Cosmochim. Acta 67, 9, 1659-1666 (2003)

[12] Muñoz-García, M.B., López-Arce, P., Fernández-Valle, M. E., Dewanckele, J., Martín-Chivelet J., Fort, R. \& Cnudde, V . Abstracts of Climate Change- The Karst Record (KR6) University of Birmingham: 99 (2011)

[13] T. Ogino, T. Suzuki, K. Sawada: Geochim. Cosmochim. Acta 51, 2757-2767 (1987) 
[14] P. López-Arce, L.S. Gomez-Villalba, L. Pinho, M.E.Fernández-Valle, M. Álvarez de Buergo, R.Fort: Mater. Charact 61, 168-184 (2010)

[15] G. Daniele, V.Taglieri: J. Cult. Herit. 11, 102-106 (2010)

[16] C. Rodriguez-Navarro, E. Ruiz-Agudo, M. Ortega-Huertas; E. Hansen: Langmuir 21, 10948-10957 (2005)

[17] L.S. Gomez-Villalba, P. López-Arce, A. Zornoza, M. Alvarez de Buergo, R. Fort: Bol. Soc. Esp. Ceram. Vidr. 50, 2, 59-66 (2011)

[18] L. Dei and B. Salvadori: J. Cult. Herit., 7, 2, 110-115 (2006)

[19] G. Ziegenbald: Proceedings of the 11th International congress on deterioration and conservation of stone III, 1109. (2008)

[20] L.S. Gomez-Villalba, P. López-Arce, M. Alvarez de Buergo, R. Fort: Appl. Phys. A (DOI: 10.1007/s00339-0116457-2)

[21] J. Rodriguez-Carvajal: Abstracts of the Satellite Meeting on Powder Diffraction of the XV Congress of the IUCR. Toulouse, France: 127 (1990)

[22] S.F. Chen, S.H. Yu, J. Jiang, F. Li, Y. Liu: Chem. Mater. 18, 115-122 (2006)

[23] J.W. Ahn, H.S. Kim, S.M. Joo, P. Kim, H. Kim, H.C. Cho: The Second Asian Particle Technology Symposium: (2003)

[24] C. Meade, R. Jeanloz: Geophys. Res. Lett. 17, 1157-1160 (1990) 

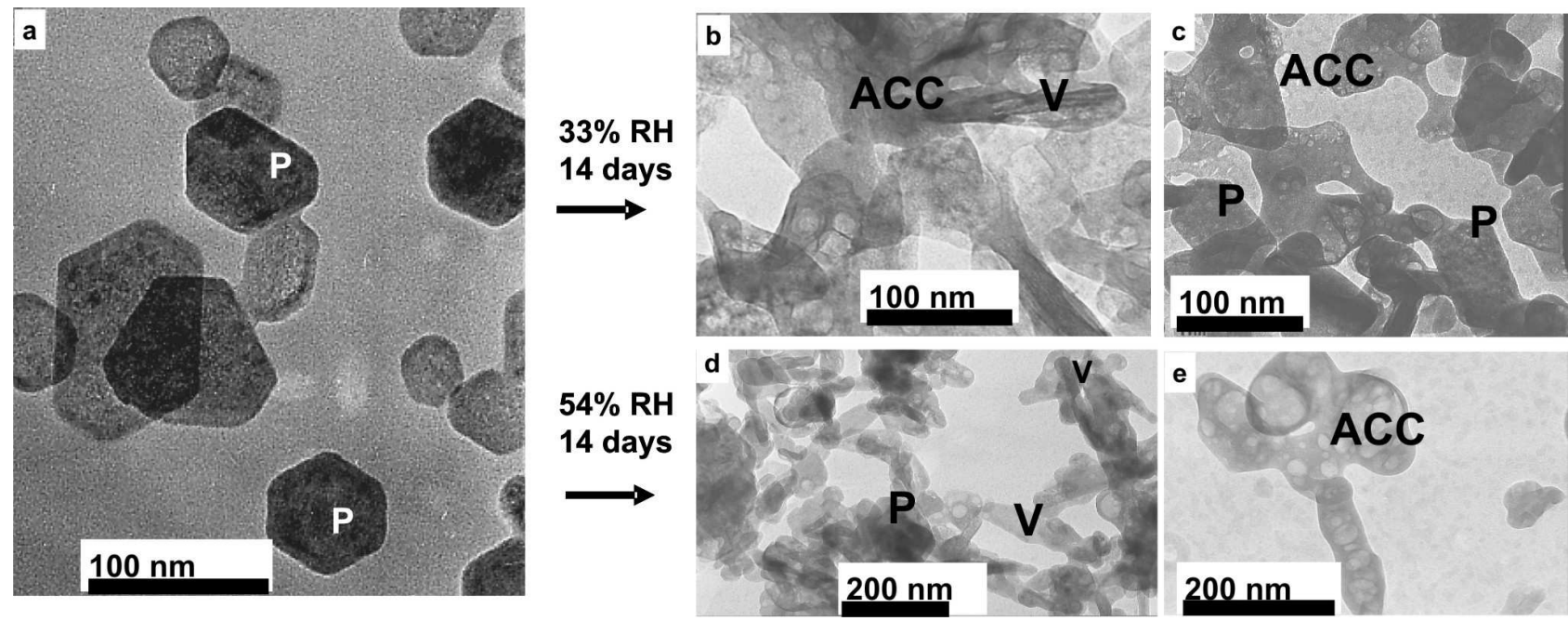

Fig. 1 TEM-bright field images of the starting solution: as deposited (P: portlandite) (a); after 14 days at 33\% RH (b) and (c); after 14 days at 54\% RH (d) and (e). (ACC: amorphous calcium carbonate, V: Vaterite, P: portlandite) 


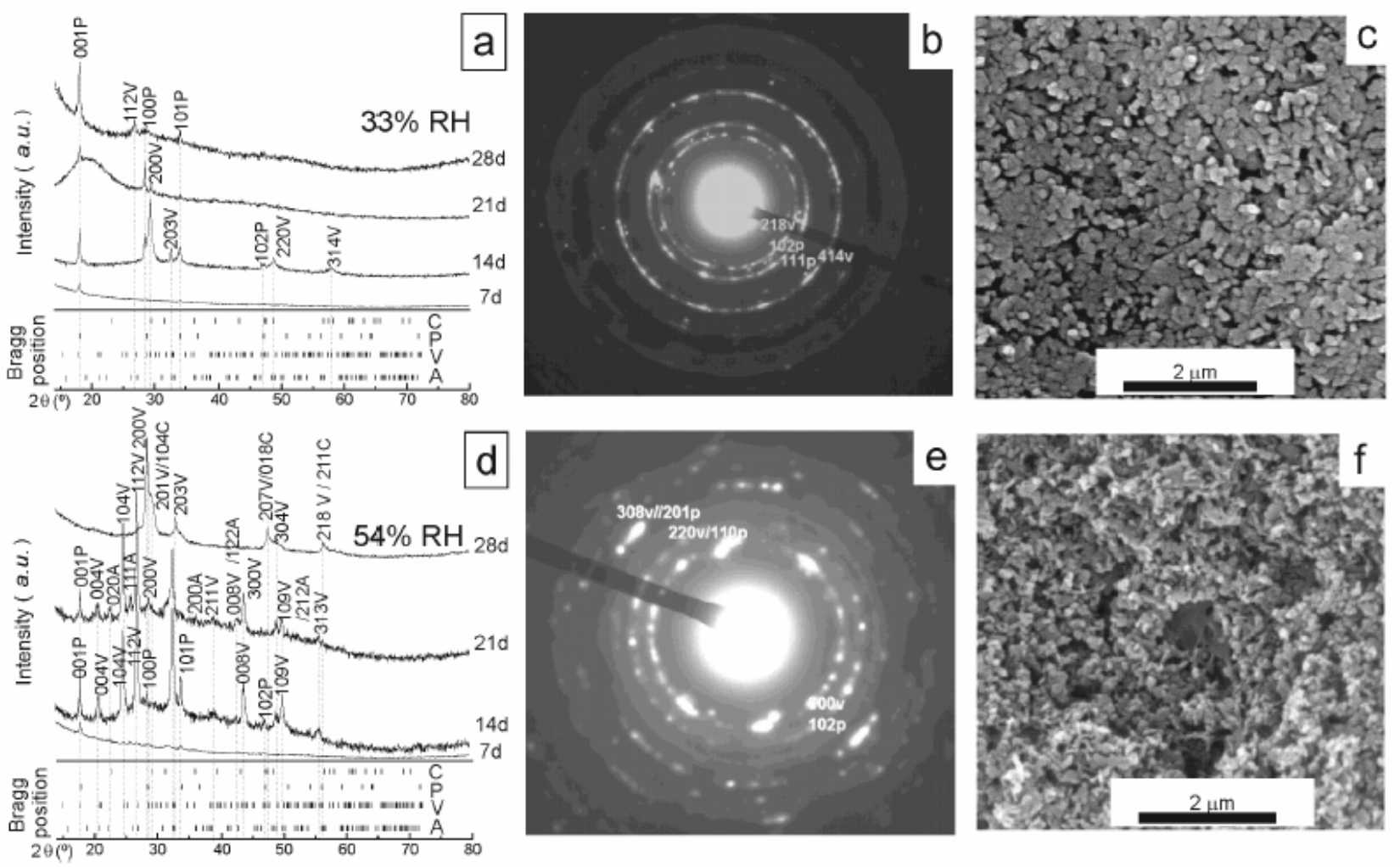

Fig 2 XRD patterns after 7, 14, 21 and 28 days at 33\% RH (a); Saed pattern after 14 days at 33\% RH (b); ESEM image after 28 days at 33\% RH (c); XRD patterns after 7, 14, 21 and 28 days at 54\% RH (d); Saed pattern after 14 days at 54\% RH (e); ESEM image after 28 days at 54\% RH (f).(C: Calcite, P: Portlandite, V: Vaterite, A: Aragonite). 
Table 1

Unit cell parameters calculated for $\mathrm{CaCO}_{3}$ polymorphs and portlandite in low humidity relative humidity $(\mathrm{RH})$ conditions

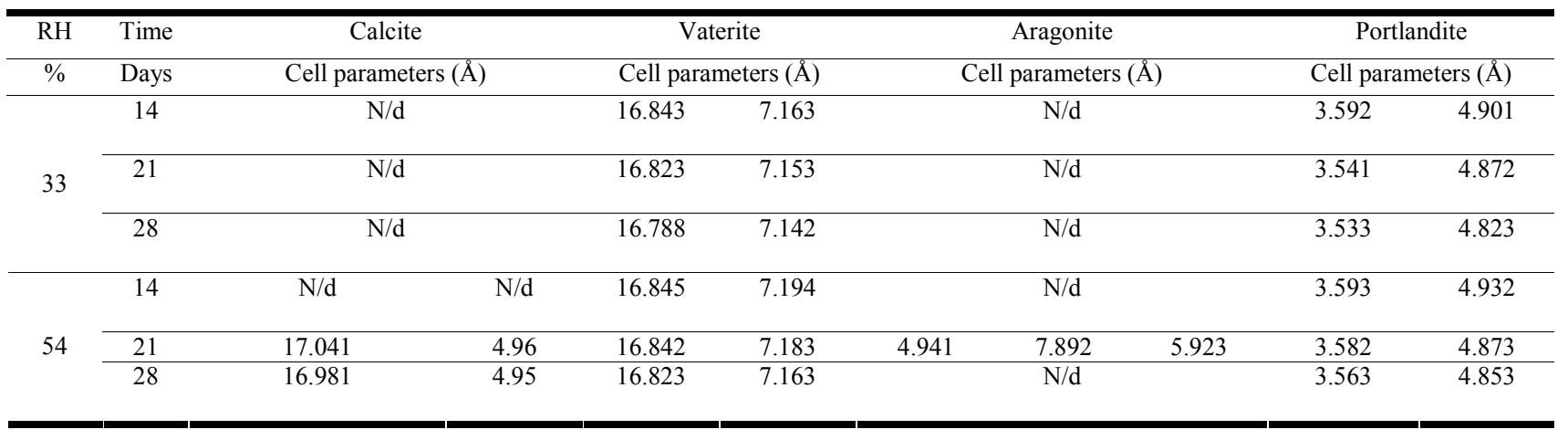

(* N/d not detected) 